\title{
Reason-based explanations and analytical sociology
}

A rejoinder to Boudon

\section{Gianluca Manzo}

\section{(2) OpenEdition}

\section{Journals}

Electronic version

URL: http://journals.openedition.org/ress/2231

DOI: $10.4000 /$ ress.2231

ISSN: 1663-4446

\section{Publisher}

Librairie Droz

\section{Printed version}

Date of publication: 1 December 2012

Number of pages: $35-65$

ISBN: 978-2-600-01704-6

ISSN: 0048-8046

\section{Electronic reference}

Gianluca Manzo, «Reason-based explanations and analytical sociology », Revue européenne des sciences sociales [Online], 50-2 | 2012, Online since 01 January 2016, connection on 19 April 2019 URL : http://journals.openedition.org/ress/2231 ; DOI : 10.4000/ress.2231 


\title{
REASON-BASED EXPLANATIONS AND \\ ANALYTICAL SOCIOLOGY \\ A REJOINDER TO BOUDON
}

\author{
GIANLUCA MANZO \\ GEMASS - CNRS / University of Paris-Sorbonne \\ glmanzo@msh-paris.fr
}

\begin{abstract}
The paper discusses Raymond Boudon's theory of ordinary rationality as well as his assessment of the so-called "analytical sociology". On the first point, the paper argues that, in order to combine the realism of an unconstrained conception of rationality with the ex-ante facto predictive power of the narrow version of rational choice theory, we should better understand the relation between potentially triggering events and the actor's "reasons". Heuristics, social identity, and emotions are regarded as good candidates to advance in that direction. On the second point, the paper recalls some factual elements suggesting that Boudon's assessment of analytical sociology is excessively severe and explains why some analytical sociologists are right in devoting especial attention to computational modelling.
\end{abstract}

Keywords: rationality, heuristics, social identity, emotions, analytical sociology, agentbased simulation.

Résumé. L'article discute la théorie de la rationalité ordinaire défendue par Raymond Boudon ainsi que son évaluation de la sociologie dite «analytique». Sur le premier point, l'article suggère que la littérature sur les heuristiques, l'identité sociale et les émotions peut aider à construire une théorie de l'action rationnelle élargie qui ne perde pas le pouvoir prédictif ex-ante facto propre à la théorie restreinte du choix rational. Sur le second point, l'article suggère que Raymond Boudon porte un jugement excessivement sévère sur la sociologie analytique et explique pourquoi certains sociologues analytiques ont des raisons fortes d'attribuer autant d'importance à la simulation informatique à base d'agents.

Mots-clés: rationalité, heuristiques, identité sociale, émotions, sociologie analytique, simulation multi-agents. 


\section{INTRODUCTION}

One of the most important findings in the contemporary philosophy of social sciences is that the materially constrained pursuit of single-minded self-interests is far from being the only way in which human rationality, hence rational action, can be conceived (see Searle, 200I). In social sciences, this fact is well reflected by the plurality of forms that, despite its apparently unifying label, the theory of rational choice has assumed over the years (Goldthorpe, 1998). This heterogeneity expresses a progressive shift from the narrow to the broad conceptions of rational action. According to the latter, all kinds of desires and constraints are admitted, full information is no longer assumed, and actors' subjectivity in constraint perception is crucial (Opp, 1999). This move away from the narrow versions of rational action theory is partly due to the lack of empirical support for its core micro-level assumptions - where experimental psychology (Shafir and LeBoeuf, 2002) and behavioral economics (Camerer and Loewenstein, 2004) played the crucial role - and partly to its explanatory failures (Ostrom, 1998).

However, the dichotomous distinction between narrow and broad versions of rational action theories tends to hide an important fact: that broad versions are not all equally broad. In this regard, the most noticeable change over the last two decades has been the diffusion of an extreme variant of broad rational choice theory in which actors' rationality is equated to having subjectively wellfounded "reasons". Rational action thus basically amounts to "reasoned action" (more than to "reasonable action": on the distinction between "rationality" and "reasonableness" see Beaney [200I]).

In economics, this point of view is endorsed by Sen (2009, p. I80), who expresses it as follows: "Rationality of choice, in this view, is primarily a matter of basing our choices - explicitly or by implication - on reasoning that we can reflectively sustain if we subject them to critical scrutiny". Reason sustainability is not only a matter of "self-scrutiny", Sen (2009, p. 196) adds, but also of "defensibility in reasoning with others" - here, Sen (2009, p. 44-46) refers back to Smith's metaphor of the "impartial spectator". Similar views can be found in political philosophy (see Rawls, 2003; Young, 2005; and Pizzorno, 2007, p. I23). 
In sociology, over the last two decades or so, Raymond Boudon has been among the scholars who have taken this open conception of rationality as a set of well-grounded subjective reasons to its furthest extent (see Boudon 1989, 1993, 1996, 1998a, 2003, and 201 I). His plea for a "reason with a small r" is based on the conviction that every other definition of rationality would be insufficient fully to account for the variety of ways in which human behaviour can be called "rational" (see Boudon, 1994, ch. 9). Similarly to Sen (2009, p. 19I-193), Boudon's extreme extension of the concept of rationality is strictly related to his intention rationally to explain not only individuals' choices of means but also their choices of ends (see Boudon, 200I).

As I read it, Boudon's “'Analytical sociology' and the explanation of beliefs” (see, in this issue, p. 7-34) is the most remarkable synthesis of his theory of rational action. To the best of my knowledge, this paper also contains his first explicit assessment of an approach to sociological theory that, over the last ten years or so, has received considerable attention around the world, i.e. so-called "analytical sociology".

I have two purposes in what follows. First, I intend to discuss what seems to me the crucial difficulty with a conception of rational action that equates "rationality" with "reasons". On this view, indeed, one can no longer benefit from the "predictive device" (Sen, 2009, p. 175, p. I83) contained in the narrower conception that frames rationality in terms of instrumental rationality. The line of reasoning that I shall seek to defend is that, in order to combine the realism of an unconstrained conception of rationality with the deductive power of the narrow version of rational choice theory, a possible solution is to look for regularities in the relation between potentially triggering events and the actor's "reasons". In particular, I shall consider heuristics, social identity, and emotions as explanatory factors which should be more systematically analysed to find such regularities. I regard this line of reasoning as one possible starting point, but not as the full answer, which would be beyond the scope of this paper. My second goal is even more modest. I intend only to recall some factual elements suggesting that Boudon's assessment of analytical sociology is excessively severe. In particular, I shall explain why computational modeling, to which analytical 
sociologists devote especial attention, is a central resource with which to test theoretical explanations referring to complex systems of individuals' reasons.

The paper is organized as follows. First, I discuss the main difficulty with an unconstrained conception of rationality à la Boudon; second, I analyze this conception of rational action in the light of important contributions on "heuristics", on "social identity, and on "emotions" in psychology, in economics, and in political science. Finally, I discuss Boudon's assessment of analytical sociology.

\section{WHAT WE CAN (NOT) DO WITH BOUDON'S THEORY OF ORDINARY RATIONALITY}

“'Analytical sociology' and the explanation of beliefs" (see p. 7-34, in this issue) contains a clear exposition of what Boudon now calls a "theory of ordinary rationality" (Boudon [1989] first adopted the label of "subjective rationality", and then that of "cognitive rationality": see, for instance, Boudon, 1996). The theory relies on the "cognitive equilibrium principle" according to which one must examine actors' reasons to find the proximate causes of their choices - in Boudon's words, "people believe that X is true, acceptable, good, legitimate, etc. as soon as they have the feeling that X rests upon a set of acceptable reasons” (““Analytical sociology'...”, p. I8 - note the similarity between this statement and Sen's definition of rational action quoted in the introduction).

Thus, the distinctiveness of Boudon's theory of rational action is that actors' reasons are completely unrestricted in the sense that no specific class of reasons is given explanatory priority. The rhetoric of cost-benefit calculation disappears behind the variety of arguments that actors can endorse and publicly defend to sustain the beliefs that motivate them to act. In the paper under discussion, Boudon demonstrates that this open conception of actors' rationality makes it possible to explain much more social regularity than allowed by the narrow version of the rational choice theory. In particular, he argues, by extending the set of acceptable reasons, it is possible to explain not only the choice of means but also the choice of ends. In this way, sociology can explain 
the genesis of complex sets of human values like individuals' feelings of justice (on this point, see, in particular, Boudon and Betton, 1999).

This achievement comes with a cost, however. To restrict actors' motivations to a specific class of reasons - instrumental reasons, in the case of the narrow variants of the rational choice theory - makes it possible to form expectations on the micro-behaviours and their macroscopic consequences that are most likely to appear, given a certain set of constraints. A given empirical observation can thus be compared with a clear benchmark that is formulated before the observation is made. As acknowledged by Sen (2009, p. I75 and p. I83), who, as we have seen, endorses a very open conception of rational action, the capacity to figure out a single outcome ex-ante facto is lost when actors' rationality is given a completely unconstrained form. On this view, the expression "rational action theory" itself is inappropriate. Strictly speaking, indeed, there is no theory, but rather a single framework in which every sort of reason-based explanation - i.e. an explanation focusing on the system of arguments that a given set of actors endorse to act in the way that they act - can be conceived.

The loss of the "predictive device", to use Sen's expression, affecting the conception of human rationality as a complex set of subjectively well-grounded reasons should be carefully distinguished from two related but analytically distinct objections usually brought against the broad versions of rational choice theory: namely their lack of deductive power, and the danger of adhocness to which they are exposed.

As correctly pointed out by Boudon (1998b, p. 195) himself, the deductive power of a theory involving individuals' reasons does not depend "on the nature of reasons mobilized in a model". Given a set of postulated "reasons", in fact, it is possible to form expectations on what behaviour is likely to appear. As no explanatory primacy is given to a specific set of "reasons", however, the deductive power only exists once the set of reasons have been postulated. But how could one achieve such a system of reasons? This question leads directly to the adhocness objection that an unrestricted conception of human rationality increases the probability that the set of hypothesized reasons will continue to be re-adjusted until it is possible to demonstrate that a given macroscopic regularity in fact derives from a population 
of actors acting in a rational way (Pizzorno, 2007, p. 65-66). As discussed at length by Opp (1999), however, this danger can be powerfully counteracted by the use of empirical data to assess the extent to which the hypothesized set of reasons is tenable. More specifically, the empirical solution says that, given a certain individual behaviour and a set of macroscopic consequences, once the set of individual reasons leading to this behaviour has been formulated, one must test whether the reasons postulated are empirically tenable. If not, one should revise the protocol of data collection and / or modify the set of hypothesized reasons.

The "empirical argument" thus amounts to an iterative procedure of post hoc theory testing which tends to be case-oriented. It only suggests that theories built on a very open conception of rational action can be falsified, but it does not help to remedy the problem of the reduced predictive power of these theories. In other words, Opp's empirical approach does not solve the problem of the variety of predictions than can be made on the basis of a conception of rational action that equates "rationality" and "reasonableness" - a problem that Boudon himself has acknowledged elsewhere (1998b, p. 195)'.

Would it be possible to go beyond the empirical approach? In particular, is there any way to combine an open conception of rationality with the predictive power of the narrow versions of the rational choice theory? My answer is that we may eventually achieve this result by identifying some mechanisms that tend systematically to trigger certain set of reasons. In this case, we would have access to a set of regularities that enable us to formulate ex-ante facto clear expectations on what micro- and macro-level outcomes are more likely to be observed ${ }^{2}$.

I Boudon's reply is that "the reconstruction of reasons is a theory and that, as soon as the elements of a theory are acceptable, because they consist of empirical data and acceptable laws, the challenge is to find another theory that would be better in some respect [...] If you do not like the latter, the challenge is this: find a better theory. We can never prove that a theory is true, only that one theory is better than another" (personal communication from Boudon's after he had read a first draft of the present paper). But this does not help solve the problem. Like Opp's empirical argument, this one only suggests that reason-based theories can be falsified. It does not address the issue of their capacity to point out ex-ante facto what system of reasons is likely to appear under certain circumstances, which is what one needs to produce ex-ante facto testable propositions.

2 The "empirical approach" can, of course, contribute to this result. In the long run, indeed, if 


\section{THREE CLASSES OF "REASON TRIGGERS"}

I propose to define a "reason trigger" as a structural or individual-level factor that increases the probability that a specific set of reasons will arise in the actor's mind. I focus here on three broad class of reason triggers that may help in finding regularity in the individuals' belief formation process, namely (i) "cognitive and social heuristics"; (ii) human invariants; (iii) "emotions". For each of these factors, I will also suggest that, while Boudon has never explicitly analyzed them in depth, none of them is in contradiction with his analysis of how reasons form in actors' minds.

\section{I. REASON-BASED EXPLANATIONS AND "HEURISTICS"}

Building on Simon's concepts of "bounded rationality" and of "heuristic search" (see, respectively, Simon, 1979; and Newell et. al. 1958), a large body of psychological literature has developed on "heuristics", i.e. cognitive shortcuts adopted by actors when they have to decide and solve problems (see Goldstein, 2009). In economics, this concept was used by Kahneman and Twersky to demonstrate that actors' reasoning is variously "biased" and that it does not conform with the way in which the narrow version of rational choice theory frames human decision-making (for an overview see Kahneman, 2003).

Readers who are familiar with Boudon's work may be surprised by my reference to this literature. In effect, Boudon has repeatedly criticized Kahneman and Twersky for treating "cognitive biases" as black boxes (see, for instance, Boudon, 1998b, p.I80; 2004, p.I86). Whilst one may agree that many of the "frames", "scripts", or "biases" mobilized in cognitive psychology and in economics are nothing more than labels - which is sometimes admitted even in the behavioral economics (see, for instance, Frederick et al., 2002, on the concept of "inter-temporal discount rate") - the so-called "fast-and-frugal heuristic" research program (Gigerenzer, 2008) studies "heuristics" in a far

it is applied systematically, one of its by-products may be the discovery of regularities in the connection between certain incentive structures and specific sets of actors' reasons. These regularities may then be incorporated into reason-based theories à la Boudon, thereby increasing their predictive capacity. 
less black-box fashion and explicitly aims to go beyond the concept of "cognitive biases" as conceived by Kahneman and Twersky.

Whilst, to the best of my knowledge, Boudon and Gigerenzer do not cite each other, their conceptions of human rationality are in fact strikingly similar. First of all, Gigerenzer (2008, p. 7) makes exactly the same criticism as Boudon of Kahneman's "heuristic-and-biases program". He maintains that "heuristics" are not directly and explicitly modeled in this research tradition, so that they end up with "mere verbal labels". Moreover, like Boudon, Gigerenzer argues that Kahneman and Twersky in fact adhere to the standard rational choice approach because they still assume that actors' rationality should comply with logic- and probability-based rules. According to Gigerenzer, it is instead the structure of the information contained in the environment in which actors are embedded that generates what is rational for them. He calls this conception of rationality "ecological rationality" (in economics, see Smith, 2008, p. 36, p. I5 I and p. 168).

This largely overlaps with Boudon's frame of rational action as "reasongrounded action". In the paper under discussion, for instance, Boudon states that, in order to understand actors' reasons, "the observer should be aware of the relevant features of the social and cognitive context in which the individual is embedded." (“'Analytical sociology'..., p. 16). Thus, according to him, magical rituals should be interpreted as perfectly rational from the point of view of those individuals who are ignorant of biological, chemical and physical mechanisms that are instead known by many contemporary observers. In the two cases, the structure of the information is simply different.

Given the strong similarity between Boudon's "ordinary rationality" and Gigerenzer's "ecological rationality", what should we expect to gain from a more systematic integration between the two theoretical perspectives? My argument is that the experimental evidence accumulated within the "fast-and-frugal heuristic" (for an overview see Gigerenzer et al., 20I I) provides useful empirical material with which to find regularities between the environment in which actors are embedded and the system of reasons that they tend to develop. We may discover, for instance, that, when information is highly skewed so that certain outcomes are rare, actors have good reasons to believe that they perform (or can 
avoid risk) better than they do in reality. Systematic links of this kind among given informational structures, beliefs, and certain mental shortcuts may help in building reason-based explanations that do not rely on a posteriori operations of reason reconstruction, thereby helping us to specify in advance the micro-level behaviour and its macroscopic consequences that are most likely to be observed.

\subsection{REASON-BASED EXPLANATIONS AND "SOCIAL IDENTITY"}

The second class of reason triggers that might be fruitfully incorporated into reason-based explanations are "human invariants", i.e., as I conceive them here, behavioral, cognitive or emotional patterns common to all human beings regardless of the culture in which they live.

At first sight, similarly to the concepts of "heuristics" and biases", that of "human invariant" may seem incompatible with Boudon's theoretical framework. In effect, the French sociologist has never concealed his distaste for "dispositional variables", which, in the paper under discussion, he defines as "conjectural causes operating in the backs of [the actors'] mind”(“"Analytical sociology'...”, p. I7). On the other hand, however, in his final comment on Durkheim's analysis of magical rituals, he judges Durkheim's explanation convincing because it introduces "either empirical statements [...] or psychological uncontroversial laws, as 'in general people want to survive”" (ibid., p. 22). Boudon is thus implicitly admitting that "dispositional variables" are legitimate explanatory factors as long as we can demonstrate that these dispositions correspond to well-defined basic individual needs or desires (see also Elster, 20II, p. 6I).

This is an extremely important point because it opens rational action theory in sociology to research in anthropology (see, for instance, Brown, 1991, 1999, 2004), in evolutionary psychology (see Pinker, 2002) and, partly, in behavioral economics (see, for instance, Henrich et al., 200I; Gächter and Herrmann, 2009) intended to establish the existence of individual invariants empirically. This literature can be of benefit to sociologists defending a conception of human rationality which equates rationality and "reason-grounded action" in that it can provide insights on universal psychological motivations that tend regularly to activate specific set of reasons. 
Among basic individual needs, an individual's desire to possess and to defend a well-defined social identity seems especially important for sociological analysis. In social psychology, it is commonplace to consider the need for social belonging as a fundamental motivation (see, for instance, Fiske, 20ı i, p. iा6). Pizzorno's and Akerlof's conceptualizations of social identity are two interesting starting points from which to assess the fruitfulness of a closer integration between reason-based explanation à la Boudon and identity-based explanations. In effect, Pizzorno overtly builds his theoretical proposal against the theory of rational choice and methodological individualism, whereas Akerlof aims to extend the standard model of the actor in mainstream economics ${ }^{3}$.

Pizzorno's (1986, p. 366-372) thesis is that social action can be framed in terms of rational action provided we accept that rationality needs identity. He explains the source of this link as follows. When an actor is choosing between, say, $\mathrm{X}$ and $\mathrm{Y}$, at time $\mathrm{t}$, according to rational action theory, he should be able to evaluate the expected benefits of the two alternatives at time $t+n$. However, Pizzorno argues, in order for this evaluation to be possible, the actor's identity should be stable over time. If not, the expected future benefits of $\mathrm{X}$ and of $\mathrm{Y}$ cannot be really evaluated and compared because the actor does not know what his point of view on $\mathrm{X}$ and on $\mathrm{Y}$ will be at time $\mathrm{t}+\mathrm{n}$. Thus, without inter-temporal identity stability, he argues, rational action is impossible. Pizzorno's proposal is that social recognition, hence the social circles that provide it, should be considered as identity "stabilizers". That is why the actor’s logic, according to Pizzorno,

3 Within the micro-foundationist tradition, Little $(1998$, ch.6) has argued that there is no incompatibility in principle between identity- and reason-based theories. Broad rationalchoice theorists have explicitly attempted to incorporate identity into the rational-choice framework. Some have done so by introducing the idea that actors are animated by a multiplicity of selves, the objective of this hypothesis being to account for some violations of the predictions that would ensue from the standard rational-theory, like the so-called weakness of will phenomenon (see, for instance, Elster, 1985, and Coleman, 1990, ch. 19). Others have tried to incorporate identity-based preferences into rational choice theory by conceiving "social identity" as a complex set of beliefs about oneself and about the group to which one thinks/wants to belong (see Aguiar and Francisco, 2009). Here my point of view is different, in that, on the one hand, I am not mobilizing social identity to remedy some explanatory failures of the narrow version of the rational choice theory, and, on the other hand, I consider the desire-component of social identity more than its belief-component. 
is driven more by the quest for sources of social recognition than by self-interest (see Aguiar and Francisco [2002] for a criticism of Pizzorno's argument).

Pizzorno's and Boudon's analytical framework are less distant that might seem. In the paper under discussion, Boudon states that actors can believe that the reasons that they endorse to act in the way that they act are strong only if they also believe that these reasons can in principle be shared by other actors. This is the concept of reason trans-subjectivity (see "'Analytical sociology'..., p. I8). Pizzorno's idea of "recognition circles” implies a similar notion: the actor needs others with similar views in order to be reassured about his identity, which is what makes belief and reason formation possible. In both cases, it is postulated that actors need to search for potential sources of (more or less) local social consensus.

A similar concern for social conformism is behind Akerlof's endeavour to devise a new approach in economics called "identity economics" (see Akerlof and Kranton, 200I). The basic assumption here is that beliefs about oneself (identity), beliefs about expected behaviors (normative beliefs, in Boudon's terminology) as a function of this identity, and choices are closely interrelated. On this basis, Akerlof and Kranton build an analytical framework that can be summarized as follows: a) actors belong to social categories; b) social categories convey beliefs about the self (actors' identity); c) social categories are also associated with norms about the prevailing behavior within the category; d) actors' utility increases/decreases if they conform with / violate these norms (ibid., p. I4 and chap. 3). Conformism assures social belonging (ibid., p. 22).

Despite the different pathways that Pizzorno and Akerlof follow to plead for an integration of identity concerns into rational action theory, both of them establishes a link among social belonging, social identity and actors' beliefs. Again, my argument is that this link can help in building reason-based explanations that lead to fine-grained predictions ex-ante facto. For instance, when actors are deeply concerned to secure their social identity, one may expect that, in order to reinforce their participation in a social group, they will be more likely to accept material and psychological costs so that collective action (see Willer, 2009) or even extreme choices like terrorist attacks (see Tosini, 20I I) become possible. 
When such concerns for social identity and status drive actor's behaviour, we can also expect them to express different convictions in different social circles, to change their minds as the networks to which they belong change, or publicly to express opinions that they do not endorse in private - the so-called "unpopular norms” (see Bicchieri, 2006, ch. 5; Centola, Willer, and Macy, 2005; Willer, Kuwabara, and Macy, 2009). Within this analytical framework that conceives the need for social identity as a fundamental human motivation, preference inconsistency can thus be anticipated and explained without introducing dubious hypotheses like that of a fragmentation of the actor's self.

\subsection{REASON-BASED EXPLANATIONS AND "EMOTIONS"}

Emotions are the last reason trigger that I shall briefly discuss as a basic micro-level element that might help to increase the predictive power of theories based on a conception of rational action as "reason-grounded action"4.

In the paper under discussion, Boudon does not address the place of emotions in the explanation of social action. Elsewhere, however, he explicitly admits that actors' emotions and actors' reasons are closely related, with the causality going in both directions, i.e. from actors' beliefs to actors' emotions and the reverse (see, for instance, Boudon, 2003b, p. 150-15 I).

This is important because, as pointed out by Frijda et al. (2000), much research has been conducted to understand how emotions are triggered by the way in which actors perceive external events (see, for instance, Scherer, 20I I). By contrast, "oddly”, say Frijda et al. (2000, p. I), the causal direction going from actors' emotions to actors' beliefs "has received scant attention". When this is the case, they remark, "the emphasis has been on the assumption that the former [emotions] distort the latter [beliefs]" (ibid., p. 2).

4 Stets and Turner (2006) provide a thorough overview of the variety of theoretical perspectives on emotions in sociology. By contrast, the empirical description of emotions is only in its early stages in sociology. As remarked by Golder and Macy (20II), large-scale web-based data might help improve this situation. 
Elster is a good example of this asymmetry within the philosophy of social science and sociology. He has focused closely on the effect that actors' cognitions (or perceptions) have on actors' emotions (for a recent overview see Elster, 20II). In particular, he has carefully studied, for each emotion, the action tendency that this emotion is likely to trigger once it has been activated by a given belief. As regards the causal link from emotion to beliefs, however, Elster's (2009) analysis only focuses on the negative consequences that emotions can have on beliefs by triggering under-investment in information (urgency) or under-estimation of the long-term consequences of action (impatience). The results are, respectively, low-quality and biased beliefs.

To deepen our understanding of emotions as "reason triggers", the "positive" role that emotion plays in belief formation should be analyzed more systematically. That actors' emotions do not necessarily distort cognitions is stressed by Scherer, for instance, who suggests that emotions can be rational in the sense that they can help actors to reach their goals (functional rationality), to make correct inferences (intellectual rationality), and to be accepted by others as persons that react in the right way (reasonable or consensual rationality). An extreme empirical example of the not-necessarily-biasing effect of actors' emotions on their beliefs is that of depressive people, who tend to assess the reality more realistically than optimistic persons (see Scherer, 20I I, p. 340). Similarly, it is often observed that fear or anxiety may induce actors to invest in information search in order to clarify their perception of what political parties offer, thereby acquiring beliefs more accurate than would be possible in the absence of such emotions (see, Jaspers, 201 I) $)^{5}$.

Among the variety of emotions that can act as "reason triggers", I regard interaction-comparison-based emotions as especially important. These are emotions, like envy, jealousy, indignation, humiliation, shame or resentment, that tend to be triggered by the comparisons that actors make within the dyadic interactions

5 The emotion-to-cognition and the cognition-to-emotion patterns can co-exist. The simplest example is a dissonance-reduction-based mechanism of belief change where two (or more) beliefs that are discrepant generate negative feelings which induce the actor to change one (or more) of his initial beliefs (see, for instance, Harmon-Jones, 2000). 
in which they are embedded. Social networks are a fundamental part of social life, and actors perform every sort of social comparison within these networks. Interaction-comparison-based emotions are thus likely to be ubiquitous, and they may lie at the origin of many of the beliefs that populate actors' minds ${ }^{6}$.

Recent research in social psychology suggests that this is a fruitful idea. Fiske (20I I) builds on an impressive amount of empirical studies to demonstrate that social comparisons tend to generate specific emotions that in turn tend to generate specific beliefs. In particular, she shows that two basic patterns are especially frequent. On the one hand, downward comparisons tend to trigger disgust and scorn, emotions that tend to induce actors to believe that people below them are less warm, less familiar, less competent, less articulate, less intelligent, and, in short, less typically human. On the other hand, upward comparisons tend to trigger envy and resentment, emotions that tend to induce actors to believe that people above them forgo their humanity to get ahead, that they are cold and calculating, even though they are competent. Coldness and competence tend to trigger the belief that wealthy people are engaged in a conspiracy and, ultimately, a threat to "us".

This is precisely the kind of evidence that we need to increase the predictive capacity of an approach equating rational action with "reason-grounded action". If we know that upward social comparison, for instance, tends to trigger specific emotions (like envy) with specific objects (like wealthy people), then we may expect to find that specific sets of reasons are also triggered in actors' minds. Members of lower and middle social groups may be more likely to think that the members of upper groups do not deserve what they have and / or that they have obtained what they have by unfair or corrupt means. As a consequence, they may also be more likely to believe that the economic organization that supports those groups should be changed. A reason-based

6 Elster (1999, p. 141-142; 2007, p. 58) distinguishes between comparison-based emotions, like envy, and interaction-based emotions like resentment. In order to draw attention to the fact that these emotions are often a by-product of the social comparisons driven by dyadic links between actors, I propose the hybrid conceptual category of "comparisoninteraction-based emotions". 
theory incorporating such emotion-belief linkages might thus be better able to predict ex-ante facto single outcomes at macroscopic level, like waves of anti- or pro-capitalist attitudes (see Jaspers 20I I, for a plea for emotions to be included in the analysis of social movements).

\subsection{THE ARGUMENT IN A NUTSHELL AND BOUDON'S EXPECTED REPLY}

The argument that I have outlined so far is that an extremely open rational action theory conceiving actors' rationality as a bundle of subjectively wellfounded reasons can profit from stronger connections with three research areas: I) the "new" literature in cognitive psychology about mental and social shortcuts, i.e. "heuristics"; 2) the literature in anthropology and in evolutionary psychology about basic and culturally invariant psychological needs; 3) the literature in cognitive psychology on emotions.

When "heuristics", "social identity", and "emotions" are considered as "reason triggers", the benefit that one may expect from integrating them into a reason-based theoretical perspective in which actors' rationality is unconstrained concerns the increase in the predictive capacity of this perspective. The more we know about the regular linkages between the structures of information in which the actors are embedded and their beliefs, among actors' networks, their social identities and their beliefs, and between actors' emotions and actors' beliefs, the more, it seems to me, we should be able to figure out a priori the micro- and macro-level outcomes observable under given social circumstances. In this way, we may eventually combine the realism of an open conception of rational action with the "predictive device", to use Sen's expression, contained in the narrower versions of the rational choice theory.

Boudon's reaction to the line of reasoning proposed would probably be that integrating cognitive-, identity-, and emotion-based mechanisms into a subjective conceptions of human rationality would expose sociologists to the risk of paying attention to unnecessary psychological details. Over the years, indeed, he has consistently defended the thesis that sociology should be based on a "conventional psychology", that is to say, a highly abstract depiction of how 
actors think and feel (see, for instance, Boudon, 2003c, p. I69-I70; 2007, p. 44, footnote I). Within the micro-foundationist tradition, among others, Coleman (1990, ch. I) and Goldthorpe (1998, p. I8I-I82) have also made a strong case against the introduction of an elaborate individual psychology into an appropriate rational action theory for sociology. Their argument is that we do not need to go into much detail about actors' psychology because the explanatory focus of sociology is the macroscopic consequences of individuals' actions. The implicit assumption behind this argument is that, where large populations of actors are concerned, psychological differences across actors cancel each other out, so that we are entitled to focus only on ideal-typical actors.

In my view, the analysis of "heuristics", "social identity", and "emotions" as "reason triggers" does not necessarily lead to a psychological-based theory of social action. My proposal certainly presupposes a stronger interaction with social and cognitive psychology; but what one should look for in this literature is a set of regularities between specific individual-level factors and the genesis of certain set of reasons, rather than details about actors' personalities and idiosyncrasies. That said, on a methodological level, we today have access to techniques that enable study of the macroscopic consequences of models of actors as complex as we want, so that we have fewer good reasons than in the past for omitting too many details at the micro-level. This is a point that I address in the next section.

\section{BOUDON AND ANALYTICAL SOCIOLOGY}

As announced in the introduction, apart from arguing for a general theory of rational action, “'Analytical sociology' and the explanation of beliefs" contains Boudon's first explicit assessment of the so-called "analytical sociology". Here it is:

I have the impression, though, that the handbooks on "analytical sociology" insist on secondary technical details and fail to identify clearly the common paradigm that underlies many illuminating sociological works, i.e. the paradigm that I have tried to identify as grounded on three principles: methodological singularism, methodological individualism and the cognitive equilibrium principle (“'Analytical sociology'...", p. 3I). 
Analytical sociology is a complex intellectual movement with respect to both its distant and proximate historical roots and its position within contemporary sociology. In other words, the diachronic and the synchronic frontiers of analytical sociology are still not well-defined (see Manzo, 20Io). Since Boudon explicitly limits his objection to the "handbooks of analytical sociology", I shall restrict myself to programmatic books on analytical sociology in assessing this objection (namely, Hedström, 2005, and Hedström and Bearman, 2009a).

To this end it is important to give more precise definition to what analytical sociology is. Hedström and Bearman's (2009b, p. 16) propose the following:

The explanatory strategy can be described as follows (see also Epstein, 2006): I. We start with a clearly delineated social fact that is to be explained; 2. We formulate different hypotheses about relevant micro-level mechanisms; 3. We translate the theoretical hypotheses into computational models; 4. We simulate the models to derive the type of social facts that each microlevel mechanism brings about; 5 . We compare the social facts generated by each model with the actually observed outcomes.

Although restrictive - more qualitative-oriented, yet analytically rigorous, scholars would consider steps 3 and 4 unnecessary (see, for instance, Elster, 2007, p. 455) - this definition is useful for discussing the two main points addressed by Boudon's critical assessment of analytical sociology: the excessive importance attributed by analytical sociologists to techniques, and their myopia with respect to the most important principles that animate all scientific sociological works.

\section{I. ARE ANALYTICAL SOCIOLOGISTS REALLY MYOPIC?}

Let me start with the second point. Although Hedström and Bearman do not use the term "methodological singularism", it seems to me that their step I clearly follows this principle. In effect, Hedström and Bearman's advice here is to focus on explananda whose temporal and spatial contours are clearly specified.

Boudon's second principle, i.e. "methodological individualism”, seems to me outlined in Hedström and Bearman's step 2, i.e. "we formulate different hypotheses about relevant micro-level mechanisms." Even more explicitly, they claim: "[...] all social facts, their structure and change, are in principle 
explicable in terms of individuals, their properties, actions, and relations to one another" (Hedström and Bearman, 2009b, p. 8). Moreover, similarly to Boudon, Hedström and Bearman (idem) also attempt to avoid the reductionist interpretation of this principle by remarking that "As we define the term, structural individualism is a methodological doctrine [that] differs from traditional notions of methodological individualism (e.g. Elster, 1982) by emphasizing the explanatory importance of relations and relational structures".

Boudon's last principle, i.e. the "cognitive equilibrium principle", which basically states that human actions must be conceived as reasonbased, also seems to be at the core of analytical sociology. In its manifesto, Hedström (2005, p. 38-39) posits: "the desires, beliefs and opportunities of an actor are here seen as the proximate causes of the actor's action and, he continues, "beliefs and desires are mental events that can be said to cause an action in the sense of providing reasons for the action”. As I stressed earlier, Boudon's fundamental contribution is to demonstrate that there is no compelling justification for restricting actors' reasons to instrumental ones. Contrary to what some critics of analytical sociology maintain (see Gross, 2009), a similar open conception of rationality as "reason-based actions" is also at the heart of analytical sociology - "DBO theory makes no assumption that actors act rationally, however; it only assumes that they act reasonably and with intention", states Hedström (2005, p. 6I, emphasis added).

Thus, the analytical sociology manifestos suggest that the three methodological principles which Boudon recognizes in every scientific sociological analysis do not animate this perspective "implicitly", as he claims. On the contrary, they are explicitly, consciously and programmatically put at the core of the approach - could it be otherwise, one may ask, given that Boudon is one of the main inspiring intellectual sources of the analytical sociology movement (see Hedström, 2005, p. 6-9 )?

7 In this respect, the following coincidence is also significant. In the paper under discussion, Boudon cites a recent article by Pawson who, according to Boudon, has "convincingly shown that the paradigm described by those three principles disentangle the meaning of "middle range theory" ("'Analytical sociology'...", p. 29). The second chapter of The Oxford 
I would expect Boudon's counter-objection to be that, if analytical sociology consists explicitly in the three-rule paradigm that he has identified, then he is fully entitled to claim that "although 'analytical sociology' is a new expression, it is actually old wine in new bottles, since it essentially revitalizes the principles more or less implicitly used by classical sociologists, notably by Weber and Durkheim” (“'Analytical sociology'..., p. 19).

That mechanism-based theorizing is at the core of classical sociology is a well-established historical fact (see, for instance, Cherkaoui, 2005, ch. I and 4). It is clearly evident to, and explicitly acknowledged by, analytical sociologists (see Hedström, 2005, p.6; Hedström and Edling, 2009). It is also clear that contemporary analytical sociology can be traced back to research in mathematical sociology, in sociological theory, and in philosophy of social sciences in the I960s and I970s (see Manzo, 2010). Moreover, it would also be easy to demonstrate that specific pieces of analytical sociology are at the heart of several strands of the theoretical and empirical literature in contemporary sociology. But does this suffice to deny the novelty of analytical sociology? I have argued elsewhere that the novelty of analytical sociology consists in its integration of epistemological, theoretical, and methodological proposals that only exist separately in the rest of the discipline (see Manzo, 20I I).

An example of this federative power of analytical sociology is the theory of action that it tries to set up. Its most distinctive feature is its attempt to endogenize the proximate causes of individuals' action, i.e. desires, beliefs, and opportunities, by taking social interactions into account (see Hedström, 2005, p. 42-59). Theoretically, this has a notable consequence: social interactions open the theory of action to ego- and alter- centered mechanisms that are usually not linked to reason-based explanations within the micro-foundationist tradition. porary incarnations of Robert K. Merton's notion of middle-range theory" (see Hedström and Udhen,2009, p. 25). 
Social interactions may induce actors to imitate each other, imitation being a heuristic-based mechanism responsible for belief and desire changes (see Gigerenzer, 2008, p. 3I). The theory of action is thus open to the literature on heuristics that I mentioned earlier (see Goldstein, 2009). Social interactions also trigger social comparisons which tend in turn to activate specific emotions. The theory of action is thus open to the literature on emotions. We saw earlier that individual and social identity is strongly related to comparison processes that take place within dyadic interactions. Social interactions thus indirectly open the analysis of belief and desire formation and change to theoretical models of action that stress identity and social recognition more than individual reasons, such as Pizzorno's framework or the recent developments in economics to which I referred earlier. Finally, taking interactions seriously into account to explain the genesis of beliefs, desires and opportunities makes it possible to establish theoretical and methodological bridges between action and network theory - something that, in the paper under discussion here, Boudon himself considers a desirable development.

One may retort that this ambition of analytical sociology to integrate different strands of the literature in order to develop a more realistic theory of action is excessive because sociology does not have methodological tools with which to study the macroscopic consequences of complex sets of micro-level mechanisms. As steps 3 and 4 of Hedström and Bearman's research strategy show, many analytical sociologists think that simulation is a promising solution.

\subsection{DO ANALYTICAL SOCIOLOGISTS HAVE GOOD REASONS TO BE TECHNIQUE-ADDICTED?}

This brings me to the second component of Boudon's caustic comment on analytical sociology, i.e. "that the handbooks on 'analytical sociology' insist on secondary technical details". My final remarks aim to explain why a specific type of simulation method, namely agent-based modeling, can in fact be regarded as a crucial resource with which to move sociology towards being a deeper and more rigorous discipline (I note in passing that Boudon was a 
strong advocate of formal modeling and simulation in the early stages of his intellectual career: see, for instance, Boudon, 1965, 1979).

What are agent-based models? The British computer scientist Michael Wooldridge (2009, p. 5) defines an agent as "a computer system that is capable of independent action on behalf of its user or owner". A single agent is thus nothing more than a computational entity. "A multiagent system", Wooldridge continues, "is one that consists of a number of agents, which interact with one another, typically by exchanging messages through some computer network infrastructure".

This class of formal models is so important for social sciences because it is infinitely flexible. Virtually any substantive mechanisms can be represented and studied within the framework of agent-based modelling. At the deepest level, this flexibility relies on the specific type of programming language adopted to build this model, namely the so-called "object-oriented programming" which allows specification of each computational entity as a set of attributes and rules and their arrangement into different relational topologies and across several levels of organization (see Hummon and Fararo, 1995).

This flexibility is especially attractive for sociologists for the following reasons. First, agent-based modeling can represent entities and have them interact at any level of analysis. A computational agent need not necessarily represent an individual. Whatever entity we wish to represent can be programmed. According to the attributes and the activities associated with the entities, agents can represent cells, atoms, molecules, individuals, organizations, groups, nations, and so forth.

Second, agent-based modeling makes it possible to introduce as much heterogeneity as believed necessary for the problem at hand. Agents can be heterogeneous in terms of attributes and/or in terms of the values they get on these attributes. More radically, agents can be heterogeneous in terms of activities, tasks, or the behavior rules by which they are driven. This is a fundamental point. As Gallegati and Kirman (1999) pointed out in their critique of mainstream economics, agent-based modeling constitutes a robust formal tool 
that indeed enables us to go beyond the metaphor of the "representative agent". In the paper under discussion, Boudon constantly refers to ideal-typical actors. In reality, actors are heterogeneous in terms of beliefs and desires, and heterogeneity matters in explaining macroscopic outcomes because heterogeneity spreads across social networks. Agent-based modeling allows us to represent heterogeneity and study its macroscopic effects.

Third, agent-based modeling is entirely agnostic about the logic of action by which agents are driven. This means that we are no longer obliged to represent actors who maximize or optimize some quantity; nor are we obliged to suppose that actors possess the very large amount of information needed to compute the future consequences of alternative choices. With respect to the theory of action, agent-based modeling is the domain of heuristics. Whatever mental or social shortcuts are assumed to be at work in the real world, we can design and study them by means of an agent-based computational model. Since the model is solved by simulation, that is to say by iterating the constitutive rules of the model several times, mathematical tractability is no longer a constraint for the kind of actors that we want to represent. This is why some have argued that agent-based modeling is the right mathematics for social sciences (see Borrill and Tesfatsion, 2010).

Finally, agent-based modeling is all about social interactions. Every network structure that we are able to imagine can be designed, and agents can be embedded within it so that their beliefs, desires, and opportunity can be seen as locally constrained and influenced by the choices of other agents and by the network's topology.

For these reasons, agent-based modeling cannot be considered a "secondary technical detail”. This class of formal models makes it possible to design theoretical models as complex as we need them to be with respect to both action logic and structural / relational constraints affecting social actions. If we are really interested in the macroscopic consequences of a given set of hypothesized micro- and interaction-based mechanisms, agent-based modeling is the most powerful method available today for the rigorous study of every substantive problem in which aggregation matters. In the late i980s, 
Coleman (1986, p. 1316) complained about the existence of "extraordinarily elaborated methods for analysis of the behavior of a set of independent entities (most often individuals), with little development of methods for characterizing systemic action resulting from the interdependent actions of members of the system". This lack of methods with which to study the micro-macro transition is in principle solved by the use of agent-based modeling.

The flexibility of this class of models may also have important consequences in resolving a fundamental difficulty with the analysis of social mechanisms. As remarked by Elster (201 I), one constantly has to deal with the problem of indeterminacy: on the one hand, the indeterminacy of the conditions that trigger a given (set of) mechanism(s); on the other, the indeterminacy of the resulting effect of mechanisms operating at the same time but in opposite directions. In both cases, agent-based modeling constitutes a powerful virtual laboratory in which to design triggering conditions and to determine the resulting microscopic and macroscopic effects of concatenations of mechanisms.

Despite these objective advantages of agent-based modeling, to what extent might the importance that many analytical sociologists attribute to this method give rise to another form of "hard obscurantism" generating essentially only "science fiction" (I borrow the two terms from Elster's (2007, p. 458-465) criticism of quantitative social sciences)? My answer is that this danger can be limited by giving priority to the so-called empirically-calibrated agent-based models (see Hedström, 2005, ch.6), that is to say, artificial societies in which agents' attributes and behavior rules rely on empirical information provided by ethnographic studies, experiments, or survey data. Although not easy, this combination is technically possible. I do believe that analytical sociology should be given the chance to prove that this is a research pathway that is worth exploring. 


\section{CONCLUSION}

I have discussed an article by Boudon which I regard as important for two reasons. On the one hand, it is a synthetic exposition of his conception of rational action as "reason-based action"; on the other, it is also Boudon's first direct assessment of the growing intellectual movement labeled "analytical sociology".

As regards the former aspect, I first pointed out that Boudon's conception of rational action is part of a more extensive shift from a narrow to a broad version of rational action theory. To some extent, Boudon's theory represents the extreme version of this trend, in that it equates rationality to the subjectively perceived reasons that an actor endorses to believe/do what he believes / does. In this respect, my argument has concerned the main problem that must be tackled when we assume that rational action amounts to "reasongrounded action", i.e. the reduced capacity to figure out ex-ante facto a single micro- or macro-level outcome that should be observed under certain social circumstances. As Boudon honestly admits, the larger the set of acceptable reasons, the less unique are the theory's predictions.

To solve this problem, I have suggested that, instead of going back to a narrower conception of rational action (as Abell [1992] suggested, for instance), we may try to accumulate regularities on "reason triggers": that is to say, micro- or structural-level facts that increase the probability that specific sets of reasons will appear to actors' minds. Among possible "reason triggers", I have focused on "heuristics", "social identity", and "emotions". In particular, I have stressed that the experimental evidence accumulated within the "fastand-frugal heuristic" research program in cognitive psychology shows systematic links among given informational structures, given beliefs, and certain mental shortcuts. Recent research in social psychology, political science, and economics on social identity conceived as a fundamental psychological need is of help in establishing regularities in the connection among social belonging, social identity and actors' beliefs that increase our capacity to predict actors' preference inconsistencies across social circles and over time. Social and cognitive psychology research on the positive, not necessarily distorting, 
role of emotions in belief formation can help in detecting regularities in actors' systems of reason, in particular when interaction-based social comparisons are at the origin of emotions like envy, jealousy, indignation, shame, or resentment.

In regard to Boudon's critical stance on analytical sociology, I have sought to show that the basic principles of this approach are identical with Boudon's conception of what scientific sociology should be. A minor disagreement concerns the stress that some analytical sociologists put on the technical side of the enterprise. On this point, my argument has been that a specific class of formal models, namely agent-based computational simulations, is in fact one of the best resources available today for the study of theoretical models based on a complex form of methodological individualism. I have suggested that this conviction does not arise from a naïve love of technicalities, but rather from the close match between the theoretical requirements of this form of methodological individualism and the structural features of the computational methodology.

\begin{abstract}
Acknowledgments: The first draft of this paper was prepared for a PhD course on "Norms, Values, and Normative Argumentation" organized by the department of sociology and human geography of the University of Oslo and held at the Centre de Coopération Franco-Norvégien in Paris in January 2012. I am very grateful to participants at this seminar, in particular Ragnvald Kalleberg and Hans Joas, for their comments and suggestions. I have also greatly benefited from discussing the article with Raymond Boudon, Karl-Dieter Opp, and Mohamed Cherkaoui, who carefully commented on a previous version of the manuscript. I have finally profited from dense discussion with James Jaspers on emotions and rationality: I thank him for kindly agreeing to meet me during his busy Paris fellowship in spring 2012. Last but not least, I wish to express my gratitude to Adrian Belton for revising my English. The usual disclaimers apply.
\end{abstract}

\title{
BIBLIOGRAPHY
}

ABELL P., 1992, "Is rational choice theory a rational choice of theory?", in James S. Coleman, Thomas J. Fararo (eds.), Rational Choice Theory. Advocacy and Critique, Newbury Park, Calif., Sage, p. 183-207. 
AGUIAR F., DE FRANCISCO A., 2002, "Rationality and Identity: A critique of Alessandro Pizzorno", European Journal of Sociology / Archives européennes de sociologie, 43-I, p. |19-131.

-, 2009, "Rational Choice, Social Identity, and Beliefs about Oneself", Philosophy of the Social Sciences, 39-4, p. 547-57l.

AKERLOF G. A., KRANTON R., 200I, Identity economics. How our identities shape our work, wages, and well-being, Princeton, Princeton University Press.

BEANEY M., 200I, "Rationality and Reasonableness", in Berit Brogaard, Barry Smith (eds.), Rationality and Irrationality: Proceedings of the $23^{\text {rd International }}$ Wittgenstein Symposium", Vienna, öbv \& hpt, p. 18-24.

BICCHIERI C., 2006, The Grammar of Society. The Nature and Dynamics of Social Norms, Cambridge, Cambridge University Press.

BORRILL P., TESFATSION L., 20I0, "Agent-based modeling: The Right Mathematics for the Social Sciences?", Working Paper n 10023 , lowa State University, Department of Economics.

BOUDON R., 1965, "Réflexion sur la logique des modèles simulés", Archives européennes de sociologie, $\mathrm{VI}-\mathrm{I}$, p. 3-20.

-, 1979, "Generating Models as a Research Strategy", in Robert K. Merton, James S. Coleman, Peter H. Rossi (eds.), Qualitative and quantitative social research, New York, The Free Press, p. 5I-64.

-, 1989, "Subjective Rationality and the Explanation of Social Behavior", Rationality and Society, 1-2, p. 171-196.

-, 1993, "Toward a Synthetic Theory of Rationality", International Studies in the Philosophy of Science, 7-I, p. 5-19.

-, 1994, The Art of Self-Persuasion, Cambridge, Polity Press.

-, 1996, "The cognitivist model. A generalized rational-choice model", Rationality and Society, 8-2, p. 123-150.

-, 1998a, "Limitations of Rational Choice Theory", American Journal of Sociology, 104-3, p. 817-828. 
-, 1998b, "Social Mechanisms without black boxes", in Peter Hedström and Richard Swedberg (eds.), Social Mechanisms. An Analytical Approach to Social Theory, Cambridge, Cambridge University Press, p. 172-203.

-, 2001, The Origin of Values, New Brunswick and London, Transaction Publishers.

-, 2003a, "Beyond Rational Choice Theory", Annual Review of Sociology, 29, p. I-2I.

-, 2003b, Raison, bonnes raison, Paris, PUF.

-, 2003c, Y a-t-il encore une sociologie?, Paris, Odile Jacob.

-, 2004, The Poverty of Relativism, Oxford, Bardwell Press.

-, 2007, Essais sur la théorie générale de la rationalité, Paris, PUF.

-, 2011, "The cognitive approach to morality", in Steven Hitlin and Stephen Vaisey (eds), Handbook of the Sociology of Morality, New York/Berlin, Springer, p. 15-33.

-, BETTON E., 1999, "Explaining the Feelings of Justice", Ethical Theory and Moral Practice, 2, p. 365-398.

BROWN D., 1991, Human Universals, New York, McGraw-Hill.

-, 1999, "Human Nature and History", History and Theory, 38, p. 138-157.

-, 2004, "Human Universals, Human Nature \& Human Culture", Daedalus, 133-4, p. 47-54.

CAMERER C. F., LOEWENSTEIN G., 2004, "Behavioral Economics: Past, Present, Future", in Colin F. Camerer, George Loewenstein, Matthew Rabin (eds.), 2004, Advances in Behavioral Economics, Princeton, Princeton University Press, p. $3-51$.

CENTOLA D., WILLER R., MACY M., 2005, "The Emperor's Dilemma: A Computational Model of Self-Enforcing Norms", American Journal of Sociology, 110-4, p. 1009-1040.

CHERKAOUI M., 2005, Invisible Codes: Essays on Generative Mechanisms, Oxford, The Bardwell Press.

COLEMAN J. S., 1990, The Foundations of Social Theory, Cambridge and London, Belknap Press of Harvard University Press. 
COLEMAN J.S., 1986, "Social Theory, Social Research and a Theory of Action", American Journal of Sociology, 91-6, p. 1309-1335.

ELSTER J. (ed.), 1985, The Multiple Self, Cambridge, Cambridge University Press.

-, 1999, Alchemies of the Mind: Rationality and the Emotions, Cambridge, Cambridge University Press.

-, 2007, Explaining Social Behaviour: More Nuts and Bolts for the Social Sciences, New York, Cambridge University Press.

-, 2009, "Emotions", in Peter Hedström, Peter Bearman (eds.) 2009a, The Oxford Handbook of Analytical Sociology, Oxford, Oxford University Press, p. 51-71.

-, 20II, "Indeterminacy of emotional mechanisms", in Pierre Demeleunaere (ed.), Analytical Sociology and Social Mechanisms, Cambridge Cambridge University Press, p. 50-63.

GROSS N., 2009, "A Pragmatist Theory of Social Mechanisms", American Sociological Review, 74, p. 358-379.

FISKE S., 20II, Envy up, Scorn down. How Status Divides Us, New York, Russell Sage.

FREDERICK S., LOEWENSTEIN G., O'DONOGHUE T., 2002, “Time Discounting and Time Preference: A Critical Review", Journal of Economic Literature, 40-2, p. 35I-40I.

FRIJDA N., MANSTEAD A. S. R., SACHA B., 2002, Emotions and Beliefs: How Feelings Influence Thoughts, Cambridge, Cambridge University Press.

GÄCHTER S., HERRMANN B., 2009, "Reciprocity, culture and human cooperation: previous insights and a new cross-cultural experiment", Phil. Trans. R. Soc. B, 364, p. 79l-806.

GALLEGATI M., KIRMAN A. P., 1999, Beyond the Representative Agent, Aldershot and Lyme, NH: Edward Elgar.

GIGERENZER G., 2008, Rationality for Mortals. How People Cope with Uncertainty, Oxford, Oxford University Press.

GIGERENZER G., HERTWIG R., PACHUR T., 20II, Heuristics. The Foundations of Adaptive Behavior, Oxford, Oxford University Press. 
GOLDER S., MACY M. W., 201I, "Diurnal and Seasonal Mood Vary with Work, Sleep and Daylength Across Diverse Cultures", Science, 333, p. 1878-1881.

GOLDSTEIN D., 2009, "Heuristics", in Hedström Peter, Bearman Peter (eds.) 2009a, The Oxford Handbook of Analytical Sociology, Oxford, Oxford University Press, p. 140-167.

GOLDTHORPE J., 1998, "Rational Action Theory for Sociology", The British Journal of Sociology, 49-2, p. 167-192.

HARMON-JONES E., 2000, "A cognitive dissonance theory perspective on the role of emotion in the maintenance and change of beliefs and attitudes", in Nico H. Frijda, Antony S. R. Manstead, Sacha Berm. (eds.), 2002, Emotions and Beliefs: How Feelings Influence Thoughts, Cambridge, Cambridge University Press, p. $185-212$.

HEDSTRÖM P., 2005. Dissecting the Social: On the Principles of Analytical Sociology, Cambridge, Cambridge University Press.

HEDSTRÖM P., BEARMAN P. (eds.), 2009a, The Oxford Handbook of Analytical Sociology, Oxford, Oxford University Press.

-, 2009b, "What is Analytical Sociology all about?", in Peter Hedström, Peter Bearman (eds.), 2009a, The Oxford Handbook of Analytical Sociology, Oxford, Oxford University Press, p. 3-24.

HEDSTRÖM P., EDLING C., 2009, "Tocqueville and analytical sociology", in Mohamed Cherkaoui, Peter Hamilton (eds.), Raymond Boudon: A Life in Sociology, Oxford, The Bardwell Press, p. 153-172

HEDSTRÖM P., UDÉHN L., 2009, "Analytical Sociology and theories of middle range", in Peter Hedström, Peter Bearman (eds.), 2009a, The Oxford Handbook of Analytical Sociology, Oxford, Oxford University Press, p. 25-47.

HENRICH J., BOYD R., BOWLES S., CAMERER C., FEHR E., GINTIS H., MCELREATH R., 200I, "In Search of Homo Economicus: Behavioral Experiments in 15 Small-Scale Societies", American Economic Review, 91, p.73-78.

HUMMON N. P., FARARO T. J., 1995, "Actors and networks as objects", Social Networks, 17-I, p. I-26. 
JASPER J. M., 201I, "Emotions and Social Movements: Twenty Years of Theory and Research", Annual Review of Sociology, 37, p. 285-303.

KAHNEMAN D., 2003, "Maps of Bounded Rationality: Psychology for Behavioral Economics", The American Economic Review, 93-5, p. I149-1475.

LITTLE D., 1998, Microfoundations, Methods, and Causation: Essays in the Philosophy of Social Sciences, New Brunswick and London, Transaction Publishers.

MANZO G., 20I0, "Analytical Sociology and Its Critics", European Journal of Sociology/Archives européennes de sociologie, 5I-I, p. 129-170.

-, 201I, "The Whole is Greater than the Sum of its Parts: Some Remarks on The Oxford Handbook of Analytical Sociology", European Sociological Review, 27-6, p. 829-835.

NEWELL A., SHAW J. C., SIMON H. A., 1958, "Elements of a Theory of Human Problem Solving", Psychological Review, 65-3, p. 151-166.

OPP K.-D., 1999, "Contending Conceptions of the Theory of Rational Action", Journal of Theoretical Politics, II-2, p. I7I-202.

OSTROM E., 1998, "A Behavioral Approach to the Rational Choice Theory of Collective Action", The American Political Science Review, 92-I, p. I-22.

PINKER S., 2002, The Blank Slate, New York, Viking.

PIZZORNO A., 1986, "Some other kind of otherness: A critique of rational choice theory", in Alejandro Foxley, Michael S. McPherson, Guillermo A. O'Donnell, Albert O. Hirschman (eds.), Development, Democracy and the Art of Trespassing: Essays in Honor of Albert O. Hirschmann, Notre Dame (III.), University of Notre Dame Press, p. 355-373.

-, 2007, II velo della diversità. Studi su razionalità e riconoscimento, Milano, Feltrinelli.

RAWLS J., 1993, Political Liberalism, New York, Columbia University Press.

SCHERER K., 20II, "On the rationality of emotions: or, When are emotions rational?", Social Science Information, 50-(3-4), p. 330-350.

SEARLE J., 200I, "The Classical Model of Rationality and Its Weaknesses", in Berit Brogaard, Barry Smith (eds.), Rationality and Irrationality: Proceedings of the 23rd International Wittgenstein Symposium", Vienna, öbv \& hpt, p. 31I-324. 
SEN A., 2009, The Idea of Justice, London, Penguin Books.

SHAFIR E., LEBOEUF R. A., 2002, "Rationality", Annual Review of Psychology, 53, p. 491-517.

SIMON H., 1979, "Rational decision making in business organizations", American economic review, 69-4, p. 493-513.

SMITH V., 2008, Rationality in Economics. Constructivist and Ecological Forms, Cambridge, Cambridge University Press.

STETS J. E., TURNER J. H., 2006, Handbook of the Sociology of Emotions, Springer.

TOSINI D., 20II, "Agents and Mechanisms of Terrorist Campaigns: A Contribution to a General Theory of Rationality", Revue européenne des sciences sociales, 49-2, p. 43-70.

WILLER R., KUWABARA K., MACY M., 2009, "The False Enforcement of Unpopular Norms", American Journal of Sociology, II5, p. 45I-490.

WILLER R., 2009, "Groups Reward Individual Sacrifice: The Status Solution to the Collective Action Problem", American Sociological Review, 74, p. 23-43.

WOOLDRIDGE M., 2009, An Introduction to Multi-Agent Systems, Glasgow, John Wiley \& Sons.

YOUNG Y., 2005, "The (Un)Reasonableness of Rawlsian Rationality", South African Journal of Philosophy, 24-4, p. 308-320. 
